[Contribution from the Laboratory of Chemical, Products Division, Standard Ori, Co. of N. J.]

\title{
PROPERTIES OF MIXTURES OF ISOPROPYL ALCOHOL AND WATER.
}

BY ROBERT B. LEBO,

Received February 16, 1921.

In working with aqueous solutions of isopropyl alcohol, it becomes necessary to know the relationship between the specific gravity, boiling point, composition of the solution and composition of the evolved vapors.

This article is divided into two parts, dealing first with specific gravity of isopropyl-alcohol-water mixtures and second with the distillation characteristic of the alcohol water mixtures. The word alcohol as used here denotes isopropyl alcohol only.

\section{Part I. Specific Gravity of Isopropyl Alcohol and Its Water Solutions.}

Several workers have in the past reported specific gravities for anhydrous isopropyl alcohol with more or less variance as follows: Thorpe ${ }^{1} 0.7903$, Doroshewski ${ }^{2} 0.7898$, Young ${ }^{3} 0.7899$, all at $15^{\circ} / 15^{\circ}$.

In making anyhdrous alcohol, the following procedure was used. Two liters of isopropyl alcohol was dehydrated as usual by mixing with fresh lime, and then distilled through an efficient rectifying column, the fraction boiling between $82^{\circ}$ and $82.4^{\circ}$ being separated and treated with anhydrous copper sulfate for two days with frequent shaking. This was then distilled thrice until a constant boiling point, $82.4^{\circ}$ (corr.), was obtained. The alcohol was treated with anhydrous copper sulfate before each distillation. The distillate was collected in an air-tight receiver and the distilling flask heated by an air-bath. $\mathrm{D}_{4}^{20}, 0.7855$, or $\mathrm{D}_{15}^{15}, 0.7902$ (pycnometer).

It is believed that the alcohol so prepared contains less than $0.10 \%$ of water. Isopropyl alcohol does not appear to hold on to water as tenaciously as does ethyl alcohol. This quantity of water would make an error less than 0.0002 in the specific gravity of the anhydrous alcohol and a proportionally smaller error for the aqueous mixtures.

The alcohol-water mixtures were made by weighing the water and alcohol in stoppered bottles. The alcohol was delivered to the bottles from a pipet operated by an atomizer bulb, no alcohol coming in contact with rubber.

$\begin{array}{lc}\text { \% Alcohol } & \mathrm{D}_{4}^{20} . \\ \text { by weight. } & 0.78556 \\ 100.00 \% & 0.80866 \\ 90.35 & 0.82282 \\ 85.09 & 0.84828 \\ 74.35 & 0.87003 \\ 65.22 & \\ 1 & \text { Thorpe, J. Chem. Soc., 71, 920 (1897). } \\ { }^{2} \text { Doroshewski, Zentr., [I], 1910, p. 157. } \\ { }^{3} \text { Young, J. Chem. Soc., 81, 728 (1902). }\end{array}$

$\begin{array}{cc}\begin{array}{c}\text { \% Alcohol } \\ \text { by weight. }\end{array} & \mathrm{D}_{4}^{20} . \\ 53.07 \% & 0.89868 \\ 43.02 & 0.92418 \\ 33.17 & 0.94590 \\ 21.39 & 0.96847 \\ 9.58 & 0.98293\end{array}$


No attempt was made to calibrate the weights used, on the basis of the absolute gram.

The results were plotted to a large scale on cross-section paper so that $0.1 \%$ could be easily read on the ordinate and $0.0002 \mathrm{sp}$. gr. on the abscissa. The points were connected by a smooth curve and from this, Table I was constructed giving the specific gravity at $20 / 4^{\circ}$ for each percentage by weight and the corresponding volume percentage.

TABLE I.

\begin{tabular}{|c|c|c|c|c|c|c|c|}
\hline & ITY 0 & isoPROP & $\Delta$ & -1 & $\mathrm{Mu}$ & $\mathrm{AT}$ & $4^{\circ}$. \\
\hline $\begin{array}{l}\text { Vol. } \\
\% \text {. }\end{array}$ & D. & $\begin{array}{l}W t . \\
\% \text {. }\end{array}$ & $\begin{array}{l}\text { Vol. } \\
\%\end{array}$ & D. & $\begin{array}{l}\text { Wt. } \\
\%\end{array}$ & $\begin{array}{l}\text { Vol. } \\
\% .\end{array}$ & D. \\
\hline 0 & 0.9983 & 34 & 41.1 & 0.9441 & 68 & 74.5 & 0.8633 \\
\hline 1.3 & 0.9963 & 35 & 42.2 & 0.9420 & 69 & 75.4 & 0.8610 \\
\hline 2.5 & 0.9945 & 36 & 43.3 & 0.9400 & 70 & 76.3 & 0.8585 \\
\hline 3.8 & 0.9927 & 37 & 44.4 & 0.9378 & 71 & 77.2 & 0.9561 \\
\hline 5.0 & 0.9910 & 38 & 45.5 & 0.9356 & 72 & 77.9 & 0.8538 \\
\hline 6.2 & 0.9894 & 39 & 46.6 & 0.9334 & 73 & 78.8 & 0.8514 \\
\hline 7.5 & 0.9878 & 40 & 47.7 & 0.9311 & 74 & 79.7 & 0.8490 \\
\hline 8.7 & 0.9863 & 41 & 48.7 & 0.9288 & 75 & 80.5 & 0.8465 \\
\hline 9.9 & 0.9848 & 42 & 49.7 & 0.9265 & 76 & 81.4 & 0.8440 \\
\hline 11.0 & 0.9834 & 43 & 50.7 & 0.9240 & 77 & 82.3 & 0.8416 \\
\hline 12.4 & 0.9821 & 44 & 51.6 & 0.9216 & 78 & 83.1 & 0.8392 \\
\hline 13.5 & 0.9809 & 45 & 52.6 & 0.9192 & 79 & 83.9 & 0.8367 \\
\hline 14.8 & 0.9798 & 46 & 53.6 & 0.9166 & 80 & 84.9 & 0.8343 \\
\hline 16.0 & 0.9787 & 47 & 54.7 & 0.9142 & 81 & 85.7 & 0.8318 \\
\hline 17.2 & 0.9777 & 48 & 55.6 & 0.9118 & 82 & 86.4 & 0.8293 \\
\hline 18.4 & 0.9766 & 49 & 56.6 & 0.9094 & 83 & 87.2 & 0.8269 \\
\hline 19.7 & 0.9755 & 50 & 57.6 & 0.9070 & 84 & 87.9 & 0.8244 \\
\hline 20.8 & 0.9744 & 51 & 58.6 & 0.9045 & 85 & 88.2 & 0.8220 \\
\hline 22.0 & 0.9732 & 52 & 59.5 & 0.9021 & 86 & 89.5 & 0.8195 \\
\hline 23.2 & 0.9718 & 53 & 60.4 & 0.8997 & 87 & 90.3 & 0.8170 \\
\hline 24.0 & 0.9704 & 54 & 61.4 & 0.8972 & 88 & 91.1 & 0.8146 \\
\hline 25.7 & 0.9689 & 55 & 62.4 & 0.8947 & 89 & 91.8 & 0.8121 \\
\hline 27.0 & 0.9670 & 56 & 63.3 & 0.8922 & 90 & 92.6 & 0.8097 \\
\hline 28.2 & 0.9652 & 57 & 64.4 & 0.8897 & 91 & 93.3 & 0.8073 \\
\hline 29.4 & 0.9635 & 58 & 65.2 & 0.8875 & 92 & 94.1 & 0.8048 \\
\hline 30.5 & 0.9616 & 59 & 66.2 & 0.8851 & 93 & 94.7 & 0.8024 \\
\hline 31.8 & 0.9598 & 60 & 67.2 & 0.8826 & 94 & 95.5 & 0.7999 \\
\hline 33.0 & 0.9578 & 61 & 68,1 & 0.8801 & 95 & 96.3 & 0.7974 \\
\hline 34.3 & 0.9559 & 62 & 69.0 & 0.8777 & 96 & 97.0 & 0.7950 \\
\hline 35.4 & 0.9541 & 63 & 69.9 & 0.8752 & 97 & 97.7 & 0.7926 \\
\hline 36.7 & 0.9521 & 64 & 70.8 & 0.8728 & 98 & 98.0 & 0.7902 \\
\hline 37.8 & 0.9501 & 65 & 71.7 & 0.8703 & 99 & 99.2 & 0.7878 \\
\hline 38.9 & 0.9482 & 66 & 72.6 & 0.8680 & 100 & 100.0 & 0.7855 \\
\hline 40.0 & 0.9461 & 67 & 73.5 & 0.8657 & $\ldots$ & $\ldots$ & \\
\hline
\end{tabular}

Table II shows the relation between temperature correction and strength of alcohol solution. This was constructed by taking specific gravity readings at three different temperatures between $10^{\circ}$ and $30^{\circ}$ on the standard solutions prepared above. Average values for change in specific 
gravity per degree were calculated from these readings and plotted against strength of alcohol. The table gives the correction for every even $10 \%$. A Westphal balance was used to obtain these data.

TABle II.-Temperature Correction.

Change in sp. gr. per degree C. Strength alcohol, \%.

10

20

30

40

50

60

70

80

90

100
Correction.

0.00019

0.00042

0.00059

0.00068

0.00074

0.00078

0.00079

0.00080

0.00080

0.00080

\section{Part II. Boiling and Condensing Points of Isopropyl-Alcohol-Water Mixtures.}

The boiling point and composition of the vapor from any liquid mixture depend upon the composition of the liquid. Very little is to be found in the literature in regard to isopropyl-alcohol-water mixtures. Doroshewski ${ }^{1}$ gives a few values which in general run higher than the boiling points reported here.

Like ethyl alcohol, isopropyl alcohol and water form a mixture boiling with constant composition for which Young ${ }^{2}$ gives $80.37^{\circ}$ as the boiling point and 87.90 the weight per cent. of the alcohol. Mixtures below this low-boiling mixture in alcohol content on boiling give off a vapor richer in alcohol than the liquid, while those having a higher alcohol content than the low-boiling mixture give off a vapor weaker in alcohol than the liquid in each case, the vapor composition tending to approach that of the low-boiling mixture.

The purpose of this work is to obtain the relation between liquid and vapor composition at the boiling point of alcohol-water mixtures which for all industrial purposes may be considered to represent equilibrium conditions. Laboratory distillations of isopropyl alcohol show that it rectifies with greater ease than does ethyl alcohol, which fact is borne out by the curves presented below.

Procedure.-The specific gravity and temperature of $700 \mathrm{cc}$. of nearly anhydrous alcohol were taken and the alcohol content determined from the specific gravity table given in Part $I$. This was placed in a short-neck liter distilling flask fitted with a thermometer graduated to $0.1^{\circ}$. Twenty cc. of alcohol was distilled at a rate of 50 to 70 drops a minute. The boiling point was read when $10 \mathrm{cc}$. of the distillate had been

1 Doroshewski, J. Russ. Phys. Chem. Soc., 42, 1448 (1910).

2 Young, $J$. Chem. Ind., 81, 728 (1902). 
obtained. The average alcoholic content in the flask before and after distillation was taken as the composition at the time the boiling point was read. To the liquid in the flask $20 \mathrm{cc}$. of water was added and the distillation carried out as before. In some cases, more water was added but enough alcohol had been previously removed to bring the contents to $700 \mathrm{cc}$. A Westphal balance was used for determining the specific gravities.

The thermometer used was previously calibrated with water and with naphthalene recrystallized from alcohol and resublimed. A constant correction of $+0.2^{\circ}$ was found. The observed temperatures were corrected for exposed mercury column by adding $C(T-t) 0.000154$ where $C$ is the length of the exposed mercury, $T$ is the observed temperature and $t$ is the room temperature. For effect of pressure on boiling point, Young ${ }^{1}$ gives for the value of $d t / d p, 0.034^{\circ} / \mathrm{mm}$. Doroshewski ${ }^{1}$ gives values ranging from $0.033^{\circ}$ for strong alcohol to $0.038^{\circ}$ for weak alcohol. The value of $0.034^{\circ}$ was used. The data are given in Table III.

The composition of the mixture boiling with constant composition was determined by numerous distillations of $250 \mathrm{cc}$. of various strengths of alcohol. These distillations were conducted with an efficient glass rectifying column the distillate being cut into two 115 -cc. fractions and, the specific gravity of each being determined at $20^{\circ}$. A Westphal balance was used until the specific gravities became nearly equal when a pycnometer was employed. These points were plotted against total volume of distillate and a straight line was drawn between the points of a single distillation.

\section{Data and Discussion.}

Table III gives the data for the liquid and vapor compositions of boiling alcoholic solutions. This is shown in graphic form in Fig. 1, where the

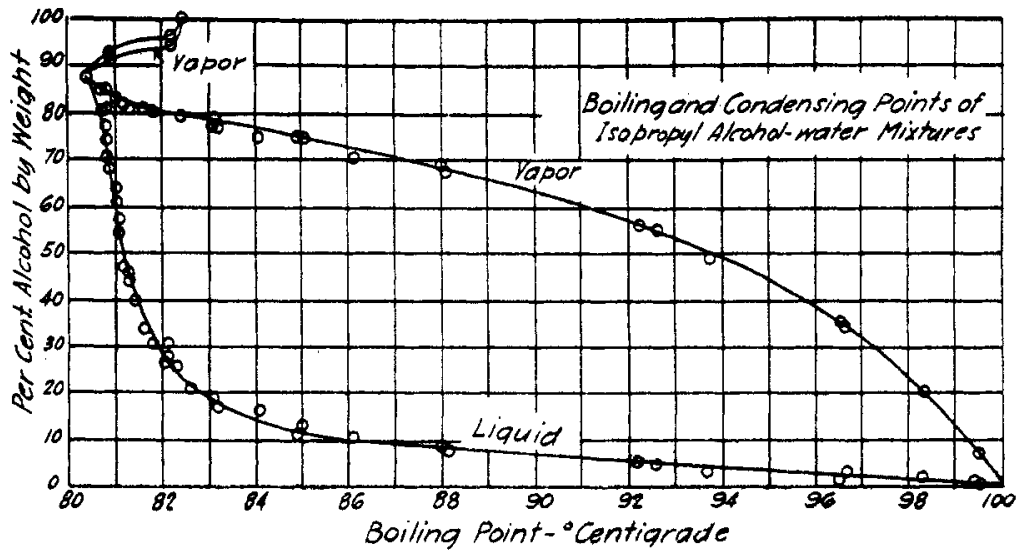

: Loci, cit.

Fig. 1. 
average strength of the content in the flask before and after distillation and the strength of distillate are plotted against boiling temperature. The lower curve represents the liquid composition in equilibrium with the vapor composition shown by the upper curve. The mixtures above the

TABLE III.

BoIling and Condenseng PoInts of isoPropyl-Alcohol-Water

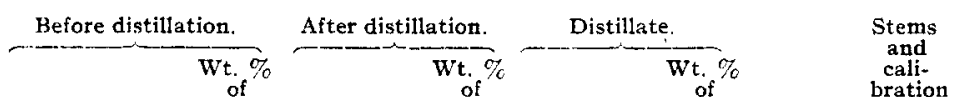

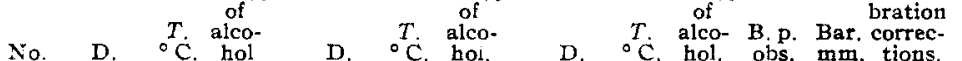

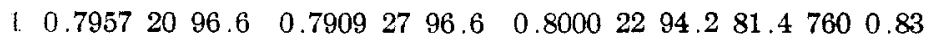

$\begin{array}{llllllllllllll}2 & 0.8063 & 20 & 92.4 & 0.8048 & 21 & 92.7 & 0.8110 & 20 & 91.5 & 80.3 & 773 & 0.95\end{array}$

$\begin{array}{llllllllllllllll}3 & 0.8146 & 21 & 88.7 & 0.8180 & 17 & 88.8 & 0.8160 & 21 & 88.2 & 80.1 & 773 & 0.88\end{array}$

$\begin{array}{lllllllllllll}4 & 0.8265 & 18 & 84.6 & 0.8231 & 22 & 84.8 & 0.8185 & 23 & 86.5 & 80.2 & 773 & 0.88\end{array}$

$\begin{array}{llllllllllllll}5 & 0.8305 & 22 & 81.8 & 0.8380 & 16 & 85.6 & 0.8220 & 21 & 85.6 & 80.3 & 773 & 0.88\end{array}$

f $\begin{array}{llllllllllllll}0.8446 & 16 & 77.9 & 0.8430 & 19 & 77.5 & 0.8272 & 18 & 84.5 & 80.3 & 774 & 0.94\end{array}$

$\begin{array}{llllllllllllll}7 & 0.8497 & 20 & 74.5 & 0.8521 & 18 & 74.0 & 0.8301 & 18 & 83.3 & 80.3 & 774 & 0.94\end{array}$

$\begin{array}{llllllllllllll}8 & 0.8586 & 18 & 71.4 & 0.8572 & 22 & 70.5 & 0.8300 & 18 & 83.3 & 80.3 & 774 & 0.94\end{array}$

$\begin{array}{llllllllllllll}9 & 0.8635 & 22 & 67.9 & 0.8625 & 25 & 67.2 & 0.8280 & 22 & 82.7 & 80.4 & 774 & 0.94\end{array}$

$\begin{array}{lllllllllllllll}10 & 0.8693 & 25 & 64.4 & 0.8736 & 22 & 63.6 & 0.8309 & 19 & 82.8 & 80.4 & 774 & 0.94\end{array}$

$\begin{array}{lllllllllllllll}111 & 0.8663 & 21 & 60.7 & 0.8850 & 10 & 59.9 & 0.8345 & 16 & 82.1 & 80 & 3 & 769 & 0.95\end{array}$

$\begin{array}{lllllllllllllll}12 & 0.8899 & 19 & 57.9 & 0.8916 & 20 & 57 & 5 & 0.8348 & 16 & 82.0 & 80.4 & 769 & 0.95\end{array}$

$\begin{array}{llllllllllllllll}13 & 0.8967 & 20 & 54.9 & 0.9020 & 17 & 53 & 5 & 0.8318 & 19 & 82.0 & 80.4 & 769 & 0.95\end{array}$

$\begin{array}{llllllllllllll}14 & 0.9075 & 17 & 51.1 & 0.9071 & 22 & 49.9 & 0.8348 & 17 & 81.7 & 80.4 & 769 & 0.95\end{array}$

$\begin{array}{lllllllllllllll}15 & 0.9116 & 22 & 48.0 & 0.9167 & 25 & 46.4 & 0.8357 & 16 & 81.6 & 80.5 & 766 & 0.95\end{array}$

$\begin{array}{llllllllllllll}16 & 0.9158 & 21 & 46.6 & 0.9179 & 22 & 45.4 & 0.8340 & 19 & 81.2 & 80.6 & 766 & 0.95\end{array}$

$\begin{array}{lllllllllllllll}17 & 0.9214 & 20 & 44.6 & 0.9242 & 20 & 43.4 & 0.8410 & 17 & 79.0 & 80.6 & 766 & 0.95\end{array}$

$\begin{array}{llllllllllllll}18 & 0.9274 & 23 & 41.2 & 0.9396 & 15 & 38.5 & 0.8337 & 21 & 80.7 & 80.6 & 766 & 0.94\end{array}$

$\begin{array}{lllllllllllllll}19 & 0.9424 & 23 & 34.7 & 0.9451 & 24 & 33.0 & 0.8366 & 20 & 79.9 & 80.4 & 759 & 0.95\end{array}$

$\begin{array}{lllllllllllllll}20 & 0.9456 & 16 & 35.2 & 0.9453 & 24 & 33.2 & 0.8338 & 21 & 80.7 & 80.3 & 749 & 0.89\end{array}$

$\begin{array}{lllllllllllllll}21 & 0.9490 & 24 & 31.3 & 0.9557 & 19 & 29.5 & 0.8345 & 22 & 80.2 & 80.6 & 749 & 0.89\end{array}$

$\begin{array}{lllllllllllllll}22 & 0.9548 & 23 & 28.8 & 0.9648 & 14 & 26.4 & 0.8380 & 21 & 79.2 & 81.1 & 757 & 0.95\end{array}$

$\begin{array}{llllllllllllllll}23 & 0.9653 & 15 & 25.7 & 0.9665 & 20 & 23.8 & 0.8394 & 19 & 78.3 & 81.1 & 757 & 0.95\end{array}$

$\begin{array}{llllllllllllll}2 \pm & 0.9610 & 20 & 26.5 & 0.9636 & 21 & 24.7 & 0.8365 & 22 & 79.3 & 81.1 & 749 & 0.89\end{array}$

$\begin{array}{llllllllllllll}25 & 0.9675 & 22 & 22.3 & 0.9704 & 21 & 21.8 & 0.6375 & 22 & 78.8 & 81.4 & 749 & 0.89\end{array}$

$\begin{array}{lllllllllllllll}26 & 0.9718 & 21 & 19.9 & 0.9747 & 20 & 18.0 & 0.8410 & 18 & 77.7 & 82.1 & 755 & 0.98\end{array}$

$\begin{array}{lllllllllllllll}27 & 0.9740 & 21 & 18.3 & 0.9764 & 21 & 16.3 & 0.8440 & 22 & 76.2 & 82.0 & 749 & 0.89\end{array}$

$\begin{array}{llllllllllllll}28 & 0.9756 & 20 & 17.4 & 0.9774 & 22 & 13.7 & 0.8480 & 18 & 75.8 & 82.9 & 755 & 1.03\end{array}$

$\begin{array}{llllllllllllll}29 & 0.9778 & 22 & 14.7 & 0.9808 & 23 & 11.8 & 0.8487 & 19 & 75.0 & 83.8 & 755 & 1.05\end{array}$

$\begin{array}{llllllllllllll}30 & 0.9813 & 20 & 12.2 & 0.9830 & 23 & 10.6 & 0.8500 & 24 & 75.3 & 83.5 & 745 & 0.90\end{array}$

31. $\begin{array}{llllllllllllll}0.9815 & 23 & 11.5 & 0.9843 & 23 & 9.3 & 0.8662 & 23 & 70.7 & 84.9 & 755 & 1.05\end{array}$

$\begin{array}{lllllllllllllll}32 & 0.9850 & 23 & 8.8 & 0.9857 & 20 & 7.9 & 0.8625 & 23 & 69.2 & 86.1 & 745 & 0.90\end{array}$

$\begin{array}{lllllllllllll}33 & 0.9846 & 23 & 9.2 & 0.9880 & 22 & 6.8 & 0.8665 & 19 & 67.6 & 86.9 & 755 & 1.05\end{array}$

$\begin{array}{llllllllllllll}34 & 0.9885 & 23 & 6.4 & 0.9910 & 24 & 4.6 & 0.8944 & 19 & 56.2 & 90.0 & 755 & 1.16\end{array}$

$\begin{array}{lllllllllllllll}35 & 0.9896 & 20 & 5.8 & 0.9928 & 20 & 3.8 & 0.8953 & 19 & 55.0 & 90.5 & 745 & 0.90\end{array}$

$\begin{array}{llllllllllllll}36 & 0.9915 & 24 & 4.2 & 0.9943 & 21 & 3.0 & 0.9098 & 17 & 49.4 & 92.6 & 764 & 1.22\end{array}$

$\begin{array}{llllllllllllll}37 & 0.9943 & 20 & 2.7 & 0.9958 & 23 & 1.8 & 0.9448 & 18 & 34.8 & 95.0 & 745 & 0.90\end{array}$

$\begin{array}{lllllllllllll}38 & 0.9943 & 21 & 2.9 & 0.9960 & 22 & 1.9 & 0.9430 & 17 & 35.3 & 95.4 & 764 & 1.30\end{array}$

$\begin{array}{llllllllllllll}39 & 0.9963 & 22 & 1.7 & 0.9974 & 24 & 0.8 & 0.9720 & 18 & 19.7 & 98.2 & 764 & 1.34\end{array}$

$\begin{array}{llllllllllllll}40 & 0.0074 & 24 & 0.8 & 0.9984 & 21 & 0.2 & 0.9872 & 19 & 7.1 & 98.4 & 764 & 1.34\end{array}$

Mixtures.

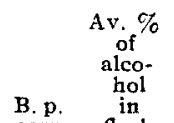

corr. flask.

82.296 .6

$80.9 \quad 92.5$

$\begin{array}{ll}80.5 & 88.7\end{array}$

$\begin{array}{ll}80.7 & 84.7\end{array}$

$80.8 \quad 81.1$

$80.8 \quad 77.7$

$80.8 \quad 74.3$

$80.8 \quad 70.9$

80.967 .5

$81.0 \quad 64.0$

$81.0 \quad 60.3$

$81.1 \quad 57.7$

81.154 .2

81.150 .5

$81.2 \cdot 47.2$

$81.3 \quad 46.0$

$81.3 \quad 44.0$

$\begin{array}{ll}81.4 & 39.8\end{array}$

$81.3 \quad 33.8$

$81.6 \quad 34.0$

$82.8 \quad 30.4$

82.127 .6

$\begin{array}{ll}82.1 & 24.7\end{array}$

$82.3 \quad 25.6$

$\begin{array}{ll}82.6 & 20.5\end{array}$

83.118 .8

$\begin{array}{ll}83.2 & 17.3\end{array}$

84.116 .5

$85.0 \quad 13.2$

$84.9 \quad 11.4$

$86.1 \quad 10.2$

$88.0 \quad 8.4$

$88.1 \quad 8.0$

92.25 .0

$92.6 \quad 4.8$

$93.7 \quad 3.6$

$\begin{array}{ll}96.6 & 2.2\end{array}$

$96.5 \quad 1.6$

$99.3 \quad 1.3$

$99.5 \quad 0.5$ 
low boiling mixture in alcoholic content are represented by the two short curves between $80.4^{\circ}$ and $82.4^{\circ}$ and are reversed, the liquid curve being

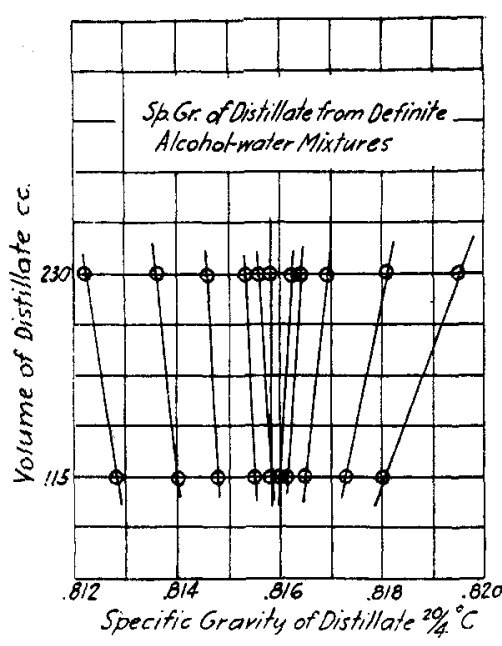

Fig. 2. above and vapor curve below. In Table IV are given the boiling and condensing points of isopropyl-alcohol-water mixtures containing less alcohol than the low-boiling mixture. These values are taken from the curves of Fig. 1. The data will differ from true equilibrium conditions by the small amount of fractionation that takes place in the flask.

The data for the distillations used in the determination of the mixture boiling with constant composition are all given in graphic form in Fig. 2. The curves for distillation of mixtures stronger in alcohol than the mixture of constant composition slope to the left, the constant-composition mixture tending to TABLE IV.

Boiling and Condensing Points of isoPropyl-Alcohol-Water Mixturas.

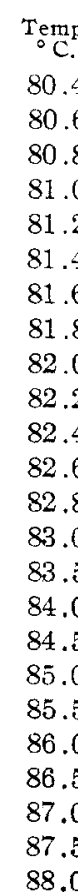

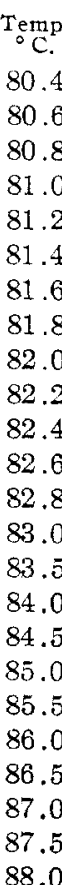

Strength of

liquid.

87.7

82.9

75.4

64.5

49.6

42.2

37.1

33.2

29.8

27.2

24.9

23.1

21.4

20.0

17.4

15.4

13.8

12.5

11.3

10.6

9.9

9.4

9.0

8.8
Strength of

vapor.

87.7

85.7

84.1

82.9

82.0

81.2

80.7

80.1

79.8

79.6

79.4

79.2

79.0

78.8

78.0

77.2

76.3

75.6

74.6

73.4

72.2

71.1

69.9

68.6

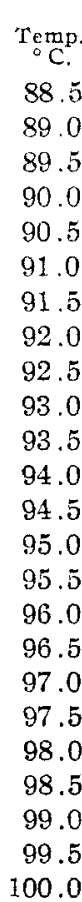

Strength of Strength of

liquid

8.4

8.1

7.8

7.3

7.0

6.7

6.3

6.0

5.7

5. 2

4.9

4.6

4.2

3.9

3.5

3,1

2.8

2.4

2.1

1.8

1.4

1.0

0.5

0.0 vapor.

67.3

65.9

64.6

63.1

61.7

60.1

58.3

56.8

54.9

53.1

51.1

48.9

46.5

43.9

41.2

38.3

35.2

31.6

27.6

23.1

18.8

13.2

7.3

0.0 
come over first and stronger alcohol later. For the mixture boiling with constant composition the curve should be vertical showing that the composition did not change while for mixtures weaker in alcohol the slope would be to the right the mixture of constant composition tending to distil first and weaker mixtures later. The boiling point was read at the end of each fraction and corrected as related before. The vertical curve representing the low boiling mixture is plotted from the following gravities of the two fractions, $D_{4}^{20} 0.81582$ and 0.81586 . On repeated distillation the value of 0.81583 was obtained. The observed constant boiling point was $79.6^{\circ}$ at $756 \mathrm{~mm}$. Adding $0.6^{\circ}$ stem correction and $0.2^{\circ}$ calibration correction gives $80.4^{\circ}$ as the boiling point of the constant-boiling mixture. By interpolation between the original data for the specific gravity table a composition of $87.70 \%$ by weight and $91.09 \%$ by volume is obtained for the alcoholic content of this mixture. A number of samples taken from a run on a large rectifying column gave an average specific gravity of 0.81583 , and ranging from 0.81570 to 0.81587 .

The greatest accuracy is obtained for the low boiling mixture, being limited only by the accuracy of the specific gravity table of Part I.

\section{Summary.}

'The specific gravity of isopropyl alcohol was found to be 0.7855 at $20 / 4^{\circ}$, its boiling point $82.4^{\circ}$ at $760 \mathrm{~mm}$. pressure. A table for specific gravity of alcohol-water mixtures is given.

The specific gravity of the mixture boiling with constant composition was found to be 0.8158 at $20 / 4^{\circ}$, its boiling point $80.4^{\circ}$ and its composition $87.70 \%$ alcohol by weight and $91.09 \%$ by volume.

Curves showing the boiling points of alcohol-water solutions and the composition of the evolved vapor are given. These curves when compared with like curves for ethyl alcohol show that isopropyl alcohol is rectified more easily than is ethyl alcohol.

BAYwAY, N, J.

[CONTRIBLTION FROM THE DEPARTMENT OF SOILS, LNIVERSITY OF WISCONSIN.]

\section{THE EFFECT OF FINELY DIVIDED MATERIAL ON THE FREEZ- ING POINTS OF WATER, BENZENE AND NITROBENZENE. ${ }^{1}$}

By F. W. PARKER.

Received February 16, 1921.

In a study of the salt content of the soil solution by different methods, including the freezing-point method of Bouyoucos and $\mathrm{McCool},{ }^{2}$ results

${ }^{1}$ Part of a thesis submitted to the University of Wisconsin in partial fulfilment of the requirements for the degree of Doctor of Philosophy. Published with the permission of the Director of the Wisconsin Agricultural Experiment Station.

The writer wishes to express his appreciation for the helpful suggestions and criticisms tendered by Prof. E. Truog.

2 Bouyoucos and McCool, Mich. Agr. Exp. Sta., Tech. Bull. 24 (1915); 31 (1917). 